\title{
O discurso bíblico-teológico ambiental na formação de práticas sociais eclesiásticas
}

\author{
The biblical-theological environmental discourse \\ in the formantion of ecclesiastical social practices
}

\section{El discurso bíblico-teológico del medio ambiente en la formación de las prácticas sociales eclesiásticas}

\author{
Amelia Ferreira Martins Limeira*
}

\begin{abstract}
RESUMO
O presente artigo pretende analisar as possibilidades, limites e contribuições da Igreja Cristã para o desenvolvimento sustentável no semiárido paraibano, realizados por meio de uma ONG Cristã Evangélica, no que tange às práticas de cuidado com o meio ambiente, com base na tradição literária bíblica. A contribuição de Padilla e Murad, que apresentam uma abordagem tanto teológica quanto missiológica em suas reflexões sobre a missão da igreja, será realçada na responsabilidade social da igreja em várias áreas, dentre as quais, a área ambiental. O tema sugere uma reflexão sobre a postura de outras igrejas evangélicas que, com base na mesma literatura, não visam o desenvolvimento sustentável de suas comunidades por meio de projetos ambientais. Esperamos demonstrar que a igreja é uma instituição social que pode contribuir, por meio de sua natureza espiritual e sua responsabilidade social, para o desenvolvimento sustentável, com base nas Escrituras Sagradas Judaico-cristãs.

Palavras-Chave: Discurso Bíblico-Teológico. Igreja - Responsabilidade Social. Desenvolvimento Sustentável.
\end{abstract}

\begin{abstract}
The article "The biblical-theological environmental discourse in the formation of ecclesiastical social practices" intends to analyze the possibilities, limits and contributions of the Christian Church for the sustainable development in the semi-arid Paraiba, carried out through an Evangelical Christian NGO, regarding the practices of care for the environment, based on biblical literary tradition. The contribution of Padilla and Murad, who present a both theological and missiological approach in their reflections on the mission of the church, will highlight the social responsibility of the church in several areas, including the environmental area. The theme suggests a reflection on the position of other evangelical churches that,
\end{abstract}

\footnotetext{
* Licenciada em Letras pela Universidade Federal da Paraíba (2005). Graduada no Curso de Teologia com concentração em Missiologia no Seminário Teológico Evangélico Betel Brasileiro, em João Pessoa, PB (2013). Mestre em Desenvolvimento e Meio Ambiente no Programa Regional de Pós-Graduação em Desenvolvimento e Meio Ambiente (Prodema) da Universidade Federal da Paraíba na área de Gerenciamento Ambiental (2011). Pastora da Primeira Igreja Evangélica Batista Cidade Verde, João Pessoa, PB. Professora do Seminário Teológico Evangélico Betel Brasileiro; do Instituto Teológico Batista de Ensino Superior, em João Pessoa, PB e da Faculdade Kurios e Faculdade de Teologia Integrada, em suas extensões em João Pessoa e Patos, PB. Pesquisadora na área de Eco(Teo)logia.
} 
based on the same literature, do not aim at the sustainable development of their communities through environmental projects. We hope to demonstrate that the church is a social institution that can contribute, through its spiritual nature and its social responsibility, to sustainable development, based on the Judeo-Christian Sacred Scriptures.

Keywords: Biblical-Theological Discourse. Church - Social Responsibility. Sustainable Development.

\section{RESUMEN}

El artículo "El discurso bíblico-teológico ambiental en la formación de prácticas sociales eclesiásticas", pretende analizar las posibilidades, límites y contribuciones de la Iglesia Cristiana para el desarrollo sostenible en el semiárido paraibano, realizados por medio de una ONG Cristiana Evangélica, en lo que se refiere a las prácticas de cuidado con el medio ambiente, con base en la tradición literaria bíblica. La contribución de Padilla y Murad, que presentan un enfoque, tanto teológico como misiológica, en sus reflexiones sobre la misión de la iglesia, se resalta la responsabilidad social de la iglesia en varias áreas, entre las cuales, el área ambiental. El tema sugiere una reflexión sobre la postura de otras iglesias evangélicas que con base en la misma literatura, no visan el desenvolvimiento sustentable de sus comunidades por medio de proyectos ambientales. Esperamos demostrar que la iglesia es una institución social que puede contribuir, a través de su naturaleza espiritual y su responsabilidad social, para el desarrollo sostenible, con base en las Escrituras sagradas judío-cristianas.

Palabras-Clave: Discurso Bíblico-Teológico. Iglesia - Responsabilidad Social. Desenvolvimiento sustentable.

\section{Considerações preliminares}

A finalidade desse artigo é expor o discurso bíblico-teológico ambiental na formação de práticas sociais eclesiásticas. Para contextualizar o problema, consideramos relevante destacar o trabalho desenvolvido pela ONG ACEV Social no semiárido paraibano, desde 1938. Sua atuação a diferencia de outras igrejas denominadas evangélicas e que, apesar de se utilizarem dos mesmos meios literários - as Escrituras Sagradas Judaico-cristãs -, parecem não ter, apesar da tradição literária bíblica e de sua argumentação teológica e missiológica, o envolvimento devido com as questões ambientais em seu relacionamento com a sociedade, por meio de projetos que visem melhorar a qualidade de vida das comunidades em seu entorno, tanto na área espiritual quanto na área social, aliando fé e prática cristãs, o que entendemos ser, muitas vezes, um problema institucional eclesiástico.

Se considermos tal omissão como um problema, algumas perguntas se fazem necessárias para trazer esclarecimentos sobre o objeto de estudo que deu origem a esse artigo, dentre as quais podemos elencar: a) Qual a relação da Teologia da Missão Integral, inspirada em René Padilla (2009) ${ }^{1}$, e por ele mesmo avaliada como sendo mais uma reflexão missiológica do que uma teologia propriamente dita, com a Eco(Teo)Logia, analisada por

\footnotetext{
No livro O que é Missão Integral?, Padilla (2009) aborda a causa da missão integral como circunstancial, em resposta às exigências sociais, para igrejas e instituições de ensino, do século XXI; uma reflexão missiológica sobre teologia, compromisso social cristão: consciência e testemunho, missão integral da igreja no mundo: evangelho e justiça social.
} 
Afonso Murad (2009) ${ }^{2}$ e pesquisada por alguns autores, não só como uma estratégia missiológica mas como uma responsabilidade social eclesiástica, que não tem, necessariamente, a obrigação de ser vista como uma teologia em tons verdes, ampliando sua visão para a integralidade do ser humano, visto de forma holística? Teria a Eco(Teo)Logia uma dimensão interdisciplinar e poderia conviver com vários aspectos no ambiente da religião, da teologia ou, ainda, da missiologia, ou seria apenas uma teologia do meio ambiente? De que modo, sem comprometer o valor sagrado da Escritura Bíblica, seria possível uma releitura ecológica da mesma? Qual a validade do conhecimento bíblico, teológico e missiológico para contribuir com o desenvolvimento sustentável em áreas de risco ambiental, considerando a separação entre Igreja e Estado, que caracteriza o país como um estado laico? Quais são as implicações filosóficas, históricas e culturais para a aplicação da Eco(Teo) Logia no Cristianismo, enquanto Teologia e enquanto Religião?

A Igreja Ação Cristã Evangélica, com sede em Patos, PB, tem suas atividades firmadas em três eixos principais: eclesiástica, missionária e social. As áreas eclesiásticas e missionárias fazem parte da estrutura de, praticamente, todas as igrejas cristãs ou não-cristãs, entretanto, a ênfase social tem sido desenvolvida, muitas vezes, como uma estratégia evangelística, ou ainda como parte da missão da comunidade religiosa que se detém na prática de boas obras como meio para a salvação. Mas, pouco se tem feito, no âmbito social, em igrejas cristãs evangélicas, para, de fato, melhorar a vida das comunidades onde estão inseridas, levando-se em conta a perspectiva holística do ser humano e a integralidade de suas necessidades bio-psico-social-espiritual, como foi trazido à tona no Movimento Social Eclesiástico Evangélico realizado em Lausanne, na Suíça, em 1974. Pela data do Congresso, em que foram estabelecidas algumas diretrizes para as igrejas em sua atuação no mundo, podemos vislumbrar que o Pacto ali assinado não influenciou ações sociais e ambientais, tais como aquelas desenvolvidas pela Igreja Ação Cristã Evangélica, uma vez que a mesma tem realizado inserções pelos sertões paraibanos desde 1938. Entretanto, poderia servir para alavancar as igrejas que participaram do evento e que são signatárias do Pacto de Lausanne a utilizarem-se do mesmo para

\footnotetext{
2 O núcleo da ecoteologia é a unidade da experiência salvífica. O autor sustenta que o elemento diferenciador da teologia ecológica ou ecoteologia não é fazer do meio ambiente o objeto da reflexão iluminada pela fé. A ecoteologia, numa relação de continuidade e ruptura com a grande tradição da Igreja, deve necessariamente articular, no interior de seu discurso, a criação em Cristo no Espírito, a história, a encarnação, a redenção e a consumação. Ao tocar cada um dos temas teológicos, deve fazê-lo em relação aos outros, numa legítima e original relação de interdependência, coerente com a lógica holística e holográfica da ecologia. Amplia o horizonte da teologia contemporânea, ao mostrar que o ecossistema participa do projeto salvífico divino. Isso tem consequências para a espiritualidade e a ética cristã.
} 
instrumentalizar suas ações e seus projetos, particularmente, na área social e, porque não dizer, ambiental.

A Igreja, de maneira geral, apesar das muitas possibilidades, está cerceada por limites financeiros, institucionais e eclesiásticos, mas pode oferecer grandes contribuições para o desenvolvimento sustentável no semiárido paraibano a partir da contribuição interdisciplinar da Eco(Teo)Logia que, enquanto princípio hermenêutico, possibilita uma releitura das Escrituras Sagradas; permite investigar pontos obscuros e controversos; admite demonstrar as implicações filosóficas, históricas e culturais de estudos no campo do sagrado; aceita conhecer textos bíblicos que recomendam o cuidado com o meio ambiente; acolhe representações do sagrado no âmbito da Ecologia nas Escrituras Sagradas Judaico-cristãs; e admite conhecer a contribuição do discurso bíblico-teológico ambiental para a formação de práticas sociais na Igreja Cristã Evangélica.

A relevância de pesquisar sobre o trabalho realizado pela ONG ACEV Social no semiárido paraibano, com vistas ao desenvolvimento sustentável, leva em conta a possibilidade de articulação e de participação dos movimentos sociais nesta esfera de atuação, ao estabelecerem relações entre os poderes públicos e eclesiásticos, investindo no poder político e social das igrejas, que, por meio de ONGs, podem repercutir a tradição judaico-cristã na busca da formação de uma nova consciência ambiental e da sustentabilidade de suas comunidades, através do desenvolvimento de políticas públicas.

O terceiro setor, aqui representado pelas ONGs, na leitura de Tachikawa (2004), pode integrar políticas públicas e igrejas, pautando suas ações na transformação social e nos princípios de liberdade, igualdade, solidariedade e fraternidade, procurando, junto às comunidades locais, modificar contextos e realidades indesejadas, como é almejado por muitos líderes, dentre eles o Pr. John Medcraft (2011), pastor presidente da Igreja Ação Cristã Evangélica.

Conhecer e avaliar a importância da Eco(Teo)Logia e sua representação no interdiscurso bíblico, teológico e hermenêutico, a fim de possibilitar uma releitura ambiental do texto sagrado, passou a figurar na agenda de algumas igrejas, que começaram a compreender sua responsabilidade no engajamento de ações que possibilitem a satisfação das necessidades básicas da população; a solidariedade para as gerações futuras; a participação da população no processo de conscientização da necessidade de conservar o ambiente; a preservação de recursos naturais; a elaboração de um sistema social garantindo emprego, segurança social e respeito a outras culturas; e a efetivação de programas educacionais, atendendo às demandas das novas agendas do social. 
Assim, o valor científico e acadêmico deste artigo está no desejo de contribuir para a análise e a proposição de discussões, em ambientes que nem sempre vinculam a espiritualidade a assuntos relacionados com as ciências, sendo imperioso levar a efeito tal empreendimento por abordar a dimensão da religião sob uma ótica inovadora e estimulante, que envolve a literatura sobre o meio ambiente e o desenvolvimento sustentável, em sua transitividade pelo sagrado.

\section{O discurso bíblico-teológico ambiental e seu lugar na igreja cristã}

Como a igreja se dedica à instrução e a educar as pessoas, segundo os seus princípios e sua doutrina, e se esforça por penetrar nas almas e por obter das vontades que se deixem conduzir e governar pela regra dos preceitos divinos, torna-se um ambiente profícuo para a educação ambiental.

Em suas "Confissões", Agostinho (2002) já meditava sobre o primeiro e o segundo capítulo de Gênesis e sobre os significados alegóricos da criação, em oposição à visão histórica que os teólogos protestantes defendem sobre a teologia da criação, propiciando um diálogo heterogêneo. Ao compreender a sociedade e a cultura emergente ao lado da ciência, Capra (1982) apresenta uma concepção filosófica e aponta para a necessidade de transformação dos paradigmas cristãos, sem o que a crise ambiental não poderia ser controlada. Weber (1999) pondera sobre a relevância da Reforma Protestante para a formação do Capitalismo Moderno, de modo que relaciona as doutrinas religiosas de crença protestante para demonstrar o surgimento de um modus operandi de relações sociais.

As igrejas, como separadas do Estado, não têm suporte legal para intervir na história dos movimentos sociais, propondo políticas públicas para a melhoria da qualidade de vida. Por isso, Tachikawa (2004), ao apresentar a importância das ONGs no Terceiro Setor, oferece possibilidades para que as igrejas, por meio do desenvolvimento de ministérios e departamentos sociais, possam encontrar a logística necessária para essa intervenção.

Eliade (2008, p. 1), particularmente, diz que "a religião é uma coisa humana, social, linguística e econômica - pois não podemos conceber o homem para além da linguagem e da vida coletiva". Para Wittmer (2004), o homem, para "ter relacionamento adequado com Deus, com outras pessoas e com o mundo" precisa entender que o céu é um lugar na terra. O grande embate do Desenvolvimento Sustentável se encontra na Economia.

O conceito de Desenvolvimento Sustentável defendido por Sachs (2002) nos dá um bom aporte teórico para fundamentar uma missiologia ecológica 
capaz de apresentar o Deus Criador, e Jesus, como a água da vida, propiciando a vida plena prometida por Jesus para o futuro, ainda no presente, uma vez que o meio ambiente e a ecologia, além das questões ambientais e suas problematizações, estão na pauta da humanidade e os estudos e análises de Leff (2001) são essenciais para a compreensão de que esta é a maior crise que o mundo já viveu. Ainda que haja resistência na discussão da dimensão espiritual da Ecologia no ambiente acadêmico, o assunto começa a encontrar subsídio e argumentos bíblicos e teológicos num ambiente que nem sempre quer relacionar religião e ciência. É isso que a professora Rosalira dos Santos diz em sua concepção discursiva (2015).

O cuidado com o meio ambiente deve ser visto como fruto de um movimento social em que a educação tem papel relevante, por propiciar o conhecimento de suas identidades e de seus desafios e, para minimizar os efeitos que o mau tratamento das questões ambientais tem recebido dos governos, é necessário que haja educação ambiental, principalmente porque atingem os mais pobres (LIMA, 2005, 2009). Essa concepção pode ser vista no tratado sobre o sofrimento que C. S. Lewis (2009) faz, sugerindo a necessidade de um envolvimento maior da Igreja com as questões sociais e, porque não dizer, socioambientais e nas obras de Leonardo Boff (2004), que demonstram a necessidade de uma postura cristã ética diante da vida criada por Deus e da necessidade de compaixão pela Terra e pelos pobres, exaltando o Evangelho Social.

Não se poderia falar de esperança para os pobres, os desvalidos e para o planeta, no século XXI, sem retomar e conhecer a Teologia da Esperança de Moltmann (2005). Tanto Haroldo quanto Ivoni Reimer $(2011,2006)$ tratam da questão da esperança, do compromisso e da ética cristã como essenciais para o cuidado com a vida e a integridade com a criação de Deus. N. T. Wright (2009) aprofunda o tema em seu livro Surpreendido pela Esperança como uma surpresa para o tempo presente com vistas à promessa de Jesus Cristo e da redenção de toda a criação de forma integral, como pode ser encontrado nos textos bíblicos. Mas, para isso, é imprescindível entender Morin (2013) que, embora pertença ao universo científico acadêmico, traz uma reflexão entusiástica sobre a questão e a necessidade de uma mudança de consciência e a igreja é um dos espaços adequados para essa conscientização e o lugar onde a Ecologia deve ser vista e tratada por meio de uma nova perspectiva cristã e reformada que compreenda o Mandado Cultural (Gênesis 1,28) e a Mordomia (Gênesis 2,15) como essenciais para a igreja hodierna e não somente para a igreja primitiva (LOPES, 2014).

Sob a perspectiva etimológica, Limeira \& Andrade (2013, p. 192) demonstram que a Eco(Teo)logia tem a ideia de oıxos [oikos = casa] $+\theta \varepsilon o ́ s$ 
$[$ Theos $=$ Deus $]+$ Aoyia $[$ loggia $=$ ciência ou estudo $]$, contudo, no campo da semântica, uma das melhores definições da Ecoteologia está na enciclopédia italiana, que a apresenta como "una forma di teologia costruttiva che si concentra sulle interrelazioni della religione e della natura, in particolare alla luce delle preoccupazioni ambientali.L'ecoteologia parte dal presupposto che esista una relazione tra la visione del mondo spirituale e il degrado della natura".

A Ecoteologia (sem os parênteses), anunciada por Silva (1996, pp. 2526), procura, desde então, convergir temas como justiça, paz e ecologia sob a perspectiva bíblica com base no Salmo 71, uma vez que "cada ser compõe um elo da imensa corrente cósmica que, na perspectiva da fé, sai de Deus e a Deus retorna”. Para Murad (2009), "a ecoteologia, numa relação de continuidade e ruptura com a grande tradição da Igreja, deve necessariamente articular, no interior de seu discurso, a criação em Cristo no Espírito, a história, a encarnação, e a consumação" com o propósito de apresentar uma Teologia adequada ao século XXI.

John Stott (2010) discute isso em seu livro $A$ missão cristã no mundo moderno, numa abordagem sobre a Teologia da Missão Integral, e aponta a integralidade do compromisso cristão com a sociedade hodierna. Dando continuidade, Stott (2014) apresenta a obra Os desafios contemporâneos para os cristãos do século $X X I$ e isso, no meu entendimento, é Eco(Teo)logia: Deus no centro de um sistema que integra não só o homem, mas toda a criação em todos os aspectos: bio-psico-social-espiritual. Wright (2012) explica que "as preocupações e ações ecológicas podem ser vistas como parte integralmente legítima da missão do povo de Deus", ao que chama Teologia Bíblica da Missão.

Apresentamos, a seguir, uma discussão sobre o tema de estudo, colocando os pontos mais obscuros ou controversos, com o propósito de salientar nossa proposta de investigação, que é conhecer a contribuição do discurso bíblico-teológico para a formação de uma igreja cujas práticas sociais considerem o desenvolvimento sustentável no escopo de suas ações eclesiásticas e ministeriais, a partir da experiência da Igreja Ação Cristã Evangélica.

\section{Estudos no campo do sagrado: pontos obscuros e controversos}

Até aqui, foi possível observar, ainda que com sutileza, a presença de pontos obscuros e controversos, tanto nas considerações preliminares, quanto no tópico $\mathrm{O}$ discurso bíblico teológico ambiental e seu lugar na igreja. A partir de então, os estudos no campo do sagrado serão o objeto de nossa reflexão. Em razão disso, neste tópico apresentaremos o ponto e o contraponto de alguns teólogos e missiólogos, considerando a possibilidade de relacionar a Eco(Teo)Logia com uma visão interdisciplinar, que pode contribuir, por 
sua ampla possibilidade de releitura dos textos sagrados, para o desenvolvimento do conceito de Teologia da Missão Integral, desenvolvido na América Latina e que se relaciona com as mais diversas frentes do saber humano, tais como as ciências sociais, a filosofia, a história, a biologia e qualquer outra área do conhecimento, que auxilie no resgate de tudo o que foi criado por Deus. Ela tem como seus principais precursores o equatoriano René Padilla, os peruanos Samuel Escobar e Pedro Arana e o porto-riquenho Orlando Costas. No Brasil, segundo Padilla (2009), as principais vozes desta Teologia são os pastores Valdir Steurnagel, Ariovaldo Ramos, Ed René Kivitz, Carlos Pinheiro Queirós, Jorge Henrique Barro e Dom Robinson Cavalcanti.

Seu surgimento aconteceu, oficialmente, em 1974, como reflexo de uma iniciativa em Berlim, realizada em 1966, em conjunto com a Associação Billy Graham. No livro O Novo Rosto da Missão, de Longuini Neto, o autor discute, de forma realista, os significados dos termos "ecumênico", "ecumenismo" e "movimento ecumênico" o que, para ele, não é fácil responder, uma vez que tanto seu conceito quanto seu significado, com base no vocábulo grego oikoumene servem para definir, de modo amplo, uma série de coisas e, em função dessa amplitude, pode perder a especificidade e o sentido verdadeiro a que se propõe.

Os termos em questão são barreiras veladas para o avanço de uma compreensão mais apurada do que é Eco(Teo)Logia, porque os líderes evangélicos evitam, muitas vezes, usar seu púlpito para a propagação de doutrinas que possam ser comparadas com ideologias verbalizadas por outras fontes religiosas. Assim, segundo Longuini Neto, os evangélicos aderem ao termo “missão" como John Stott $(2010,2014)$, por exemplo, muito embora o objetivo final seja promover a inserção dos cristãos na sociedade, em tantas áreas quanto sejam possíveis, com vistas à sua transformação.

A organização do CLADE I (Congresso Latino-Americano de Evangelização), em 1969, na cidade de Bogotá - como uma reação crítica ao projeto norte-americano de reduzir o conceito de evangelização e o surgimento da Fraternidade Teológica Latino-Americana tiveram seus desdobramentos com o Movimento Lausanne, que reuniu cristãos procedentes de mais de cento e cinquenta nações e gerou o Pacto de Lausanne, um dos documentos mais importantes do século XX para os evangélicos, segundo John Stott, relator do Pacto de Lausanne (2003), em que tenta esclarecer a distinção entre o que é holístico - que defende uma visão integral e um entendimento geral dos fenômenos -, do que é integral - que não tem qualquer falta, diminuição ou redução, ou ainda, que tem todos os componentes ou propriedades originais. Como é possível notar, há uma compreensão equivocada dos termos quando de sua tradução para a língua portuguesa. 
O Pacto de Lausanne contribuiu para o aperfeiçoamento de uma Teologia da Missão Integral, defendida por Padilla (2009), particularmente para a América Latina, ao difundir que a igreja que se compromete com a Missão Integral entende que seu propósito não é chegar a ser grande, rica ou politicamente influente, mas, sim, encarnar os valores do reino de Deus e manifestar o amor e a justiça, em âmbito pessoal e comunitário.

A Teologia da Missão Integral, uma vertente teológica evangélica desenvolvida na América Latina, que considera a dignidade humana, o cuidado com o meio ambiente e a luta contra toda forma de opressão e injustiça como aspectos indissociáveis da mensagem do Evangelho, pode ser vista como uma nova teologia ou uma perspectiva missiológica, possibilitando à igreja alguns meios para alcançar o seu objetivo maior: a transformação do homem nos aspectos espirituais, emocionais e pessoais, de forma integral e integrada, de acordo com o Pacto de Lausanne, o que poderia ser realizado por meio da possibilidade interdisciplinar da Eco(Teo)Logia.

Segundo a Teologia da Missão Integral, sob a vertente de uma leitura hermenêutica com base na Eco(Teo)Logia, Deus criou o mundo como expressão do seu amor e, sendo o ser humano feito à imagem e semelhança de Deus, é ele quem recebe a incumbência de Deus para cuidar da sua criação (Mandato Cultural - Gênesis 1,26-28). O pecado é a atitude deliberada da humanidade de resistir a este propósito (Queda - Gênesis 3). E Jesus, portanto, veio reconciliar o ser humano com Deus (Redenção - Gênesis $3,15)$ e, assim, reestabelecer o propósito de Deus para a humanidade e toda a sua criação (Mordomia - Gênesis 2,15), por meio daqueles que seguem a Jesus (Romanos 8,22), até que novos céus e nova terra sejam criados (Apocalipse 21).

Nos últimos anos, o mundo tem registrado um estado de profunda crise mundial, complexa, multidimensional que, segundo Capra (2006, p. 21), afeta todos os aspectos da vida cotidiana: saúde, modo de vida, meio ambiente, relações sociais, economia, tecnologia e política, com dimensões intelectuais, morais e espirituais, sem precedentes na história da humanidade, em que nos deparamos com a ameaça da extinção da raça humana e de toda forma de vida existente no planeta. É preciso encontrar, como proposto por Morin (2013, p. 189), o caminho de um pensamento multidimensional que integre e desenvolva formalização e quantificação, entendendo que a realidade antropossocial é multidimensional e contém o individual, o social e o biológico; e multifacetada nos aspectos econômico, psicológico e demográfico, procurando encontrar o caminho de um pensamento dialógico no suporte teórico de Bakhtin (2011). 
Os textos de Gênesis 1,28 e 2,15 têm sido cooptados para justificar o domínio do homem sobre toda a criação. Lewis (2009, p. 155) diz que "o homem foi designado por Deus para que tivesse domínio sobre os animais, e tudo o que um homem faça a um animal ou é um exercício legítimo ou um abuso sacrílego de uma autoridade concedida pelo direito Divino". Lewis legitima o cuidado, admitindo a impossibilidade de interpretação de textos isolados das Escrituras Sagradas e os princípios divinos e eternos que as inspiraram utilizando-se da hermenêutica bíblica histórico-gramatical defendida por Zuck (1994).

Segundo John Stott (2011, p. 43), na criação, Deus estabeleceu para os seres humanos três tipos fundamentais de relacionamento: com ele, entre si e com a boa terra e as criaturas sobre as quais ele os estabeleceu. Ao explicar a visão centrada na natureza como criação de Deus, John Houghton (apud WRIGHT, 2012) diz que "our responsibility is to manage it as God's stewards, answerable to him. Being conscious of the needs of both humans and wildlife, it provides in some ways a synthesis between anthropocentric and eco-centric approaches, although with the added divine dimension". Sobre isso, Wright (2012) explica que "as preocupações e ações ecológicas podem ser vistas como parte integralmente legítima da missão do povo de Deus" (2012).

\section{Eco(Teo)Logia: dimensão interdisciplinar versus aplicação nas Escrituras Sagradas}

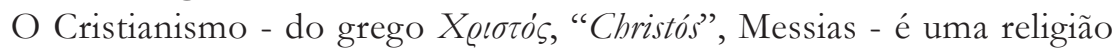
monoteísta, que é apresentada no Antigo Testamento por meio do chamado de Abraão, seu patriarca, e no Novo Testamento se mostra centrada na vida e nos ensinamentos de Jesus de Nazaré. A fé cristã acredita, essencialmente, em Jesus como o Cristo, Filho de Deus, Salvador e Senhor. A religião cristã tem três vertentes principais: o Catolicismo Romano - subordinado ao bispo romano - a Ortodoxia Oriental - que se dividiu de Roma em 1054 após o Grande Cisma - e o Protestantismo - que surgiu durante a Reforma do século XVI. Os cristãos acreditam que Jesus Cristo é o Filho de Deus, que se tornou homem e o Salvador da humanidade, morrendo pelos pecados do mundo.

Segundo o Criacionismo, Deus criou todas as coisas a partir da manifestação de Sua Palavra e estabeleceu com toda a criação uma aliança a partir de Adão, o primeiro homem e de sua mulher Eva, já que era um só; diante da desobediência e do descumprimento da parte que cabia ao homem na aliança, o casal é expulso da presença de Deus e só depois do nascimento de Enoque, filho do casal, o Senhor passa a ser novamente invocado. Da geração de Enoque, que foi transladado, veio a existir Noé e sua família, que, tendo 
sido achados íntegros numa terra contaminada pela corrupção do gênero humano, recebe a graça de serem chamados para uma aliança com Deus: desta vez Noé e sua família são privilegiados e obedecem à voz de Deus construindo a arca em que seria preservada toda a criação de Deus, já que este havia decidido destruir toda a terra, em toda a sua extensão. Então, temos em Adão uma aliança - não comerás do fruto da árvore que se encontra no meio do jardim - e em Noé - preservarei você e sua família tão somente se, obedecendo, construísse uma arca segundo a orientação de Deus. Depois de a arca estar pronta, Deus ordenou que toda a família entrasse na arca e um casal de cada espécie de animal recebeu a mesma ordem, obedecendo. $\mathrm{Na}$ sequência, veio o dilúvio que destruiu toda a terra e tudo o que era vivo, quer seja animal ou vegetal. Ao final de cento e cinquenta dias, passados o dilúvio e suas consequências, Noé e sua família puderam sair da arca com todos os animais preservados e Noé erigiu um altar ao Senhor cumprindo sua parte na aliança. Outra aliança a que se refere o Antigo Testamento é a aliança de Deus com Abrão, quando o Senhor o chama da terra de Ur dos Caldeus e ordena que ele deixe sua terra e a sua parentela e parta para uma terra que lhe mostraria prometendo que faria dele uma grande nação. Abrão obedeceu ao Senhor e ficou, por isso, conhecido como o pai da fé. Deus dá a Abrão e Sara, sua esposa, um filho em sua velhice e a este transfere a benção que havia sido dada a Abraão. Isaque é o seu nome e seus herdeiros são os judeus que vivem hoje em Israel e dispersos em várias partes do mundo à espera daquele que os livrariam do jugo de seus inimigos e que governaria, como rei, a nação de Israel. Apesar de Israel ser o filho de Abraão sobre quem estava a benção e a promessa, Abraão teve um filho com Agar, escrava egípcia, antes dele - sendo então o seu primogênito - Ismael - a quem Deus prometeu a Abraão fazer, a partir dele, uma grande nação - que são os palestinos (CAIRNS, 2008; CURTIS; LANG \& PETERSEN, 2003; GONZÁLEZ, 2011).

As guerras, que se estabelecem desde a fundação do estado de Israel, em 1948, e perduram até os dias de hoje, têm fulcro nas promessas bíblicas dadas a Isaque e a Ismael, decorrentes de uma promessa anterior dada a seu pai Abraão. Mesmo diante de uma exposição tão prolongada sobre a narrativa bíblica, a mesma ajuda-nos a entender os conflitos que irrompem na Palestina e o modo como os judeus e palestinos desejam se apropriar da terra em função da mesma promessa feita a seu pai, Abraão, conforme descrito nas Escrituras Sagradas, conhecidas por eles como "Torá".

Deus ainda faz, no Antigo Testamento, alianças com Moisés, o libertador, para retirar o povo israelita que, por quatrocentos e trinta anos esteve 
escravo no Egito, tipificando o próprio Cristo que, por seu sangue, liberta do pecado e da escravidão ao sistema desse mundo. Tanto o Antigo Testamento quanto o Novo Testamento fazem referência ao cuidado com a terra, com o povo, com a mordomia da criação, com o mandato cultural e, num contexto mais amplo, numa leitura eco(teo)lógica, incluindo a questão do meio ambiente, sob a perspectiva central de Deus.

A Eco(Teo)Logia, ainda que não possa ser vista como uma teologia bíblica, como sugerem alguns autores já mencionados, pode ser analisada e contribuir para a possibilidade de uma leitura das Escrituras em que fé e obras possam caminhar juntas e em que o crer e o realizar possam contribuir para a melhoria de vida das pessoas mais carentes e menos beneficiadas pelas políticas públicas em nossa sociedade, que não incentivam a educação, a cultura, a arte, a música, o respeito à cidadania e o conhecimento dos direitos, enquanto cidadãos.

A Eco(Teo)Logia se propõe a uma leitura bíblica teocêntrica - com Deus no centro - e a partir dEle o envolvimento com a sua criação, porque esta aguarda, ansiosamente, pela salvação que virá por meio dos filhos de Deus. A Igreja deve ser o instrumento motivacional para que possa haver leis e políticas públicas que beneficiem os fracos e os oprimidos, a despeito da teologia da libertação de Leonardo Boff. A Igreja tem, nas Escrituras Sagradas, a sua regra de fé e prática e o que é preciso é que seus líderes assumam a sua responsabilidade social diante de Deus e diante dos homens para que os propósitos de Deus e seus ensinamentos possam ser materializados em nossas comunidades cristãs ou não cristãs, porque, segundo entendemos, a abordagem da teologia bíblica focada na Eco(Teo)logia pode ser um instrumento para a conscientização ambiental e contribuir para a formação de uma nova consciência e engajamento ecológicos por parte da igreja evangélica, independente de conceitos humanos sobre ecumenismo ou outras variáveis religiosas.

Apesar da observância dessa constatação, esse discurso encontra-se ainda muito restrito a certas esferas institucionais, não alcançando contingentes mais amplos de evangélicos, por isso, esse artigo procura questionar e compreender como os textos bíblicos podem inspirar uma visão eco(teo) lógica, visando apresentar o modo como o discurso teológico pode, de fato, contribuir para a conscientização ambiental, apresentando as práticas institucional e eclesiástica do discurso teológico ambiental evangélico em diversos níveis e conhecendo sua resistência por parte de alguns pastores e igrejas.

\section{A representação da ecologia nas Escrituras Sagradas}

A formação do cânon bíblico se deu gradualmente e foi formado num período aproximado de mil e quinhentos anos. Os cristãos protestantes acreditam que o último livro do Antigo Testamento foi escrito pelo profeta 
Malaquias. Para estes, o Antigo Testamento é dividido em quatro partes: Pentateuco, Históricos, Poéticos e Proféticos; e o Novo Testamento é composto pelos Evangelhos, Atos, Epístolas Pastorais e Apocalipse, conforme os estudos de Berkhof (1990).

Segundo a literatura judaica, Esdras, na qualidade de escriba e sacerdote, presidiu um conselho formado por cento e vinte membros chamado Grande Sinagoga, que teria selecionado e preservado os rolos sagrados. Alguns acreditam que, naquele tempo, o cânon das Escrituras do Antigo Testamento foi fixado (Esdras 7:10,14), entretanto, esta tese é desacreditada pela crítica moderna. Os estudiosos concordam que foi essa mesma entidade que reorganizou a vida religiosa nacional dos repatriados e, mais tarde, deu origem ao Supremo Tribunal Judaico, denominado Sinédrio. Para os judeus, o Antigo Testamento é dividido em três partes: Lei, Salmos e Profetas. Os judeus não consideram o Novo Testamento em sua tradição literária sagrada, de acordo com Walker (1967).

A discussão entre Religião e Ciência tem despertado o debate em setores distintos da sociedade e da academia e, em busca de conciliar os escritos sagrados com a crise ambiental, pode-se perceber um significativo aumento da produção literária sobre esse assunto, principalmente, a partir da divulgação da Carta da Terra que, sob a dimensão da arte, apresenta o planeta como ambiente sagrado, passando a ser considerado não apenas na dimensão do natural, mas, sobretudo, na esfera da espiritualidade, como diz Rosalira dos Santos ao explicar que "a crise ambiental é também uma crise espiritual e de valores que desafia nosso modelo de civilização".

De acordo com Hegel (2001, pp. 32-37), quando a arte se situa na mesma esfera da religião e da filosofia, torna-se um modo de trazer à consciência e exprimir o divino, evocando os interesses mais profundos da humanidade e as verdades mais abrangentes do espírito - manifestos com a Carta da Terra. Por outro lado, a concepção cristã de verdade exige mais do que a determinação de transitar entre o sensível e o poder nela encontrado, mas a convicção de que a verdade tem sua representação no Verbo que se fez carne e habitou entre os homens cheio de graça e verdade (João 1:14), e que, segundo ele mesmo, é o caminho, a verdade e a vida (João 14:6). Para o apóstolo João, a arte não proporciona a satisfação das necessidades espirituais que épocas e povos do passado nela procuravam e que só no sagrado encontraram, mesmo que o seu resultado seja decorrentes do espírito, como afirma Hegel (2001).

${ }^{3}$ Ouvindo uma terra que fala: dimensões espirituais da ecologia ou dimensões ecológicas da espiritualidade. Rosalira Dos Santos é pesquisadora da Fundação Joaquim Nabuco. 
No entanto, se toda obra de arte pertence à sua época, ao seu povo, ao seu ambiente e depende de concepções e fins particulares, históricos e de outra ordem, conforme descreve Hegel (2001, pp. 38-48), as Escrituras Sagradas Judaico-cristãs não podem ser vistas, meramente, como uma obra literária porque é atemporal e supracultural. O apóstolo Paulo assim declara "Toda Escritura é divinamente inspirada e proveitosa para ensinar, para repreender, para corrigir, para instruir em justiça” (II Timóteo 3:16).

Os cuidados com a criação fazem parte da "Missio Dei". A Missio Dei é um termo teológico cunhado por Christopher Wright em seu livro $A$ missão do povo de Deus: uma teologia bíblica da missão da Igreja. Segundo o autor, Deus está reivindicando o mundo inteiro para si, de forma implacável e, em seu livro, ele demonstra como o seu plano, visto de uma perspectiva mais abrangente, dirige os propósitos do povo de Deus, a igreja (WRIGHT, 2012) e a Ecologia proporciona oportunidades, conforme escreve Batty (2012), para que esta missão possa ser realizada por meio de "meeting people in a christian context, to discover nature as God's creation; demonstrating practical christian care for creation; using environmental issues as teaching and evangelistic opportunities", ou seja, "conhecer pessoas em um contexto cristão para descobrir a natureza como criação de Deus; demonstrando cuidado prático para com a criação; usando as questões ambientais como ensino e oportunidades evangelísticas". Dave Bookless (2008, p. 136) diz que "o cuidado para com a criação, do qual a Bíblia fala, é o primeiro elemento da adoração e do serviço a Deus".

Apesar de reconhecer a existência de uma diversidade de representações do sagrado no âmbito da ecologia, nosso objetivo principal é aprofundar a relação entre a $\mathrm{Eco}(\mathrm{Teo}) \operatorname{logia}$ e o Cristianismo, enquanto literatura e religião, a partir de textos bíblicos do Antigo e do Novo Testamento da Bíblia Sagrada considerando as possibilidades que o Cristianismo tem, segundo Schaeffer (1976), de contribuir para a restauração de cada uma das áreas afetadas pelo mau uso dos recursos do planeta.

\section{Igreja cristã: possibilidades, limites e contribuições para o desenvolvimento sustentável}

As igrejas que situam suas ações no semiárido paraibano, que demonstram compreender seu papel político e social, são relevantes na transformação de realidades indesejadas e na modificação de contextos sociais porque, de acordo com Wittmer (2004, p. 83) "A vida cristã, longe de nos tornar superespirituais, seres quase angelicais, é, na verdade, uma busca pela recuperação de nossa humanidade".

Suas contribuições não devem se limitar a ações socioeducativas ou assistencialistas, como descreve Lima (2005), já que os maiores desafios desta 
região são decorrentes de fenômenos naturais como falta de chuvas. Entretanto, esse desafio não se concentra no ecológico, mas em romper paradigmas históricos, políticos e culturais, incentivando a participação popular em busca de políticas baseadas não apenas no agronegócio e no assistencialismo, que tem sido preponderantes na região, mas que reivindiquem do poder público a construção e a aplicação de políticas, que possam atender aos anseios e às prioridades essenciais das comunidades locais.

Dentre as possibilidades concretas de atuação da igreja cristã, podemos destacar a ONG ACEV Social que, por meio de seu Programa Sertão Sustentável promove o Programa de Desenvolvimento Comunitário Rural, que compreende cinco projetos: Poços, Plantação, 4 Pernas, Agroflorestal e Doce Sertão, atuando em parceria com as ONGs Tearfund, Borda Comunicações, Aliança Evangélica, Mãos Dadas, Renas e a Igreja Ação Evangélica. Além da ACEV Social, há outras ONGs envidando esforços para a preservação e proteção ambiental do semiárido paraibano, como o Instituto Ambiental Pico do Jabre, em Maturéia, PB, a ONG SOS Sertão; a Rede Cáritas, com o apoio financeiro da cooperação espanhola Manos Unidas e do Banco do Nordeste do Brasil (BNB); e, por último, a Visão Mundial ${ }^{4}$ que atua em parceria com o Projeto de Tecnologia Alternativa Comunitária (PATAC) da Paraíba.

Os projetos socioambientais desenvolvidos pelas ONGs supracitadas corroboram com os princípios e concepções de Capra ${ }^{5}$ (1982, p. 14; 2002) quando diz que "Precisamos, pois, de um novo paradigma - uma nova visão da realidade, uma mudança fundamental em nossos pensamentos" e de Sachs (2002, pp. 85-89) que aponta oito dimensões da sustentabilidade, quais sejam: o alcance de um patamar razoável de homogeneidade social; o equilíbrio entre respeito à tradição e inovação; a preservação do potencial do capital natural na sua produção de recursos renováveis e a limitação do uso dos recursos não renováveis; respeitar e realçar a capacidade de autodepuração dos ecossistemas naturais; a superação das disparidades inter-regionais; o desenvolvimento econômico intersetorial equilibrado; a apropriação universal dos direitos humanos; e a eficácia do sistema político internacional, o que, segundo esperamos, poderá contribuir para descrever a atuação, possibilida-

\footnotetext{
4 A Visão Mundial é uma organização não governamental humanitária que tem como objetivo ajudar aqueles que mais necessitam! Atuam há 41 anos no Brasil ajudando crianças e adolescentes a terem acesso à programas sociais que levam educação, lazer e saúde às comunidades mais carentes do país. Além disso, a Visão Mundial é parceira da World Vision Internacional, que está presente em mais de 100 países lutando para erradicar a pobreza e garantir condições de vida mais justas para pessoas carentes ou que estão em situação de vulnerabilidade, principalmente os mais jovens.

5 Fritjof Capra dirige a ONG CEA (Centro de Estudos Ambientais) defendendo o coletivo contra a crise ecológica, desde 1983.
} 
des, limites e contribuições da igreja para o desenvolvimento sustentável no semiárido paraibano.

A partir da ideia de esgotamento dos recursos renováveis do planeta, o homem prossegue na "obsessão pela regeneração" crendo num tempo cíclico, no eterno retorno, na destruição periódica da humanidade, no prefácio de um novo universo e de uma nova humanidade "regenerada" da criação para o caos descrito por Eliade (1996, p. 330) e revelados na Bíblia Sagrada como a criação de novos céus e nova terra (Apocalipse 21).

A dificuldade em priorizar o social em detrimento do político está ancorada na resistência de se estabelecer uma relação satisfatória entre consciência ambiental e desenvolvimento sustentável, tomando como base a definição mais aceita para desenvolvimento sustentável, que é a produzida pelo Relatório Brundtland, com base no binômio "o desenvolvimento capaz de suprir as necessidades da geração atual, sem comprometer a capacidade de atender as necessidades das futuras gerações" (1987).

\section{Considerações finais}

Com base no referencial teórico apresentado, chegamos a algumas considerações: que a Missão Integral não deve ser vista como uma teologia, mas como uma reflexão sobre a relevância do papel institucional da igreja no século XXI e que a Eco(Teo)Logia pode ser vista como um viés hermenêutico para a interpretação bíblica e uma re(leitura) ecológica das Escrituras Sagradas. Os dois termos, assim como Padilla e Murad, autores exponenciais desse discurso têm, todavia, a função de promover a integração do homem a Deus e à Sua Criação, difundindo: compromisso e consciência social, palavra e ação, evangelho e justiça social.

Além disso, foi possível notar que há possibilidade de a Eco(Teo)Logia ter uma dimensão interdisciplinar e não ser apenas uma Teologia do Meio Ambiente, em virtude de a mesma transitar em diversos campos disciplinares e estar muito além de ser uma teologia voltada apenas para as questões ambientais; que uma re(leitura) ecológica da Bíblia, no âmbito espiritual, não compromete seu valor divino e sagrado; que os textos bíblicos e os comentários teológicos podem ser validados contribuindo com o desenvolvimento sustentável podendo ser a resposta da igreja cristã hodierna à crise ambiental; que implicações filosóficas, históricas e culturais para a aplicação da Eco(Teo) Logia no Cristianismo, devem ser vistas com naturalidade, procurando sua compatibilidade com a missão do povo de Deus; que a repercussão desta visão socioambiental junto às igrejas cristãs evangélicas, que atuam no semiárido paraibano, já pode ser notada, embora ainda haja muito a fazer e que isso 
pode ser realizado por meio da educação cristã e da conscientização ambiental bíblica; que, ao desenvolver atividades socioambientais no entorno de suas comunidades, as igrejas se utilizam de associações e ONGs para conscientizar e usufruir de políticas públicas que beneficiem suas comunidades extrapolando os limites de suas possibilidades como igreja por sua natureza espiritual.

Esse tem sido o foco a Igreja Cristã Evangélica, com sede em Patos, PB, no semiárido paraibano: possibilitar a adaptação de comunidades do sertão dos estados da Paraíba e Pernambuco às atuais mudanças climáticas mediante a contribuição para a solução de uma das necessidades mais básicas e um direito fundamental do homem: água para beber; promover o desenvolvimento sustentável por meio da inclusão produtiva do sertanejo, o que leva ao desenvolvimento do potencial de transformação da realidade socioeconômica da região; e combater a desertificação do semiárido nordestino em seus diversos aspectos, sob a égide da preservação do bioma e do ecossistema da caatinga do nordeste brasileiro.

De acordo com os autores visitados, tanto no ambiente das ciências quanto da teologia, essa parece ser uma alternativa urgente que emerge da religião através de um processo de conscientização, já que o homem tem em sua alma sonhos salvacionistas movidos pela esperança, de que através de sua experiência, possa provocar uma mudança de paradigmas socioeconômicos que possam trazer benefícios para as questões ambientais e Lopes (2011) diz que a humanidade precisa ter em sua agenda de compromissos a preocupação constante sobre os efeitos econômicos e ambientais do aquecimento global, mantendo esses compromissos em suas agendas eclesiásticas diárias.

Esperamos ter promovido uma reflexão sobre o discurso bíblico-teológico ambiental na formação de práticas sociais eclesiásticas contemporâneas, reconhecendo sua base bíblica e sua fundamentação teológica assim como avaliando as possibilidades, limites e contribuições da igreja cristã para o desenvolvimento sustentável, identificando a representação da ecologia nas Escrituras, admitindo a dimensão interdisciplinar da Eco(Teo)Logia e estudando os pontos obscuros e controversos no campo do sagrado vivenciado pelos cristãos evangélicos.

\section{Referências bibliográficas}

AGNOL, R. D. Salvar a Terra: a contribuição da Teologia para a ética do cuidado na ecologia. X Salão de Iniciação Cientifica. PUC-RS, 2009. Disponível em: http://www.pucrs.br. Acesso em: 16 de ago. de 2016.

AGOSTINHO, S. Confissões. São Paulo: Paulus, 2002.

ANDRADE, M. T. D. Técnica da pesquisa bibliográfica. 3. ed. São Paulo: USP-Faculdade de Saúde Pública, 1972. 
ANDRADE, M. O. de. Interfaces do saber ambiental. In: ANDRADE, M. Oliveira de. (Org.). Sociedade, Natureza e Desenvolvimento. João Pessoa: Editora Universitária da UFPB, 2004.

ANDRADE, M. O. de. Diálogo de Saberes. Em busca de uma epistemologia ambiental. In: ANDRADE, M. O. de. (Org.). Meio ambiente e desenvolvimento: bases para uma formação interdisciplinar. João Pessoa: Editora Universitária da UFPB, 2008.

BAKHTIN, M. Estética da criação verbal. São Paulo: Martins Fontes, 2011.

BATTY, L. Ecology in mission. Essay submitted as requirement for the Christian Ethics Module, FdA/BA in Theology and Ministry Studies. Lincoln: Lincoln School of Theology, 2012.

BERKHOF, L. Princípios de interpretação bíblica. 3. ed. São Paulo: Cultura Cristã, 2008.

BÍBLIA. Nova Versão Internacional. Disponível em: https://www.bibliaonline.com.br/nvi. Acesso em: 16 de ago. de 2016.

BOFF, L. Saber cuidar: ética do humano, compaixão pela terra. 9. ed. Petrópolis: Vozes, 2004.

BOOKLESS, D. Planetwise: dare to care for God's world. Notthingham: IVP, 2008.

CAIRNS, E. E. O Cristianismo através dos séculos: uma história da igreja cristã. 2. ed. São Paulo: Vida Nova, 2008.

CAPRA, F. O ponto de mutação: a ciência, a sociedade e a cultura emergente. São Paulo: Cultrix, 1982.

CARTA DA TERRA. Valores e princípios para um futuro sustentável. Secretaria do Meio Ambiente. Prefeitura de Cuiabá, 2000.

CURTIS, A. K; LANG, J. S.; PETERSEN, R. Os 100 acontecimentos mais importantes da bistória do cristianismo. São Paulo: Editora Saraiva, 2003.

ELIADE, M. Tratado de história das religiões. São Paulo: Martins Fontes, 2008.

FOUCAUlT, M. A ordem do discurso. Petrópolis: Vozes, 2011.

GIL, A. C. Como elaborar projetos de pesquisa. 3. ed. São Paulo: Atlas, 1996.

GOHN, M. G. Teorias dos movimentos sociais: paradigmas clássicos e contemporâneos. São Paulo: Loyola, 1999.

GONZÁLEZ, J. L. História ilustrada do cristianismo. São Paulo: Vida Nova, 2011.

HEGEL, G. W. F. Cursos de estética I. 2. ed. rev. São Paulo: Editora da Universidade de São Paulo, 2001.

LAUSANNE, Série. Pacto de Lausanne: comentados por John Stott. São Paulo: ABU, 2003.

LEFF, E. Educação Ambiental e Desenvolvimento Sustentável. In: REIGOTA, Marcos.

Verde cotidiano: o meio ambiente em discussão. Rio de Janeiro: DP\&A, 2001.

LEWIS, C. S. O problema do sofrimento. São Paulo: Editora Vida, 2009.

LIMA, G. F. da C. A diferenciação do campo da EA no Brasil: concepções, identidades e disputas. In: LIMA, G. F. da C. Teorias e práticas em educação ambiental. Mossoró: UERN, 2009.

LIMA, G. F. da C. O ambiente como movimento social. In: LIMA, G. F. da C. Formação e dinâmica do campo da educação ambiental no Brasil: emergência, identidades e desafios. 
Campinas: Universidade Estadual de Campinas, 2005. 207 p. Tese de Doutorado. Departamento de Sociologia do Instituto de Filosofia e Ciências Humanas da Universidade Estadual de Campinas, Campinas, 2005. Disponível em: http://ecomarapendi.org.br/Rebea/ Arquivos/GustavoLima_teseUNICAMP.pdf. Acesso em: 16 de ago. de 2016.

LIMEIRA, A. F. M.; ANDRADE, M. O. de. Eco(Teo)logia: discurso teológico ambiental x prática comunitária evangélica. Revista Desenvolvimento e Meio Ambiente, vol. 28, p. 189-204, jul./dez. 2013.

LOPES, A. N. G. Ecologia: uma perspectiva cristã-reformada. Disponível em: http://www. mackenzie.br. Acesso em: 16 de ago. de 2016.

MAÇANEIRO, M. Religiões, ecologia e sustentabilidade. Disponível em: www.itesc.ecumenismo. com. Acesso em: 16 de ago. de 2016.

MEDCRAFT, J. ACEV Brasil: ACEV Social. Disponível em: http://www.acevbrasil.org. br/. Acesso em: 16 de ago. de 2016.

MOLTMANN, J. Teologia da esperança. São Paulo: Edições Loyola, 2005.

MORIN, E. Ciência com consciência. 15. ed. Rio de Janeiro: Bertrand Brasil, 2013.

MURAD, A. T. O núcleo da ecoteologia e a unidade da experiência salvífica. Revista Pistis Práxis, 2009.

NORTHCOTT, M. S. The environment and Christian ethics. Cambridge: Cambridge University Press, 1996.

PADILLA, C. R. O que é missão integral?. Viçosa: Ultimato, 2009.

REIMER, H. Paz na criação de Deus: esperança e compromisso. Estudos Teológicos São Leopoldo. Vol. 51, n. 1, p. 138-156, jan./jun. 2011. Disponível em: http://www.est.edu.br/ periodicos. Acesso em: 16 de ago. de 2016.

REIMER, I. R. Criação e Bíblia. In: REIMER, Ivoni Richter (Org.). Curso de Verão Ano XX. Ecologia: cuidar da vida e da integridade da criação. São Paulo: Paulus, 2006.

SACHS, I. Caminhos para o desenvolvimento sustentável. Rio de Janeiro: Editora Garamond, 2002.

SANTOS, R. dos. Ouvindo uma Terra que fala: dimensões espirituais da ecologia ou dimensões ecológicas da espiritualidade. Reunião Equatorial de Antropologia: X Reunião de Antropólogos Norte-Nordeste. Livro de Resumos. Mesas Redondas. Disponível em: http:// www.exitoeventos.com.br/xabannerea/resumos_rea.pdf. Acesso em: 16 de ago. de 2016.

SCHAEFFER, F. Polvição e a morte do homem: uma perspectiva cristã da ecologia. Rio de Janeiro: Juerp, 1976.

SILVA, J. A. A. A conferência da ONU sobre o meio ambiente e o desenvolvimento (ECO 92). A contribuição da igreja à conferência e ao debate. Por que uma ecoteologia?. In: OLIVEIRA, Nair de Assis. Ecoteologia agostiniana. São Paulo: Paulus, 1996.

STOTT, J. A missão cristã no mundo moderno. Viçosa: Editora Ultimato, 2010.

STOTT, J. Os cristãos e os desafios contemporâneos. Viçosa: Editora Ultimato, 2014.

TACHIKAWA, T. Organizações não governamentais e Terceiro Setor: criação de ONGs e estratégias de atuação. 2. ed. São Paulo: Atlas, 2004.

WALKER, W. História da Igreja Cristã. São Paulo: ASTE, 1967. 
WEBER, M. A ética protestante e o espírito do capitalismo. 14. ed. São Paulo: Editora Pioneira, 1999.

WITTMER, M. E. Heaven is a place on earth: why everything you do matters to God. Grand Rapids: Zondervan, 2004.

WRIGHT, C. J. H. A missão do povo de Deus: uma teologia bíblica da missão da igreja. São Paulo: Editora Vida Nova, 2012.

WRIGHT, N. T. Surpreendido pela esperança. Viçosa: Editora Ultimato, 2009.

ZUCK, R.. B. A interpretação bíblica. São Paulo: Vida Nova, 1994.

Submetido em: 20-10-2016

Aceito em: 7-6-2016 